\title{
High power impulse magnetron sputtering of $\mathrm{Zn} / \mathrm{Al}$ target in an $\mathrm{Ar}$ and $\mathrm{Ar} /$ $\mathrm{O}_{2}$ atmosphere: The study of sputtering process and AZO films
}

\author{
M. Zubkins*, H. Arslan, L. Bikse, J. Purans \\ Institute of Solid State Physics, University of Latvia, Kengaraga 8, LV-1063 Riga, Latvia
}

A R T I C L E I N F O

\section{Keywords:}

HiPIMS

Sustained self-sputtering

Reactive sputtering

ZnO:Al (AZO) films

Room temperature deposition

\begin{abstract}
A B S T R A C T
Reactive high power impulse magnetron sputtering (R-HiPIMS) has been demonstrated as a promising technique for the $\mathrm{ZnO}: \mathrm{Al}$ (AZO) thin film deposition at low temperature with improved electrical properties compared to the reactive direct current magnetron sputtering (R-dcMS). However, there are not enough studies about the HiPIMS process using Zn/Al target itself. Additionally, AZO films have not been deposited with the pulse duration times long enough to allow the discharge to develop into the self-sputtering mode. $C$ - $V$ - $t$ characteristics and the time average plasma optical emission spectra were studied as a function of different sputtering parameters, such as frequency, average power, pulse duration time, and oxygen flow rate. AZO films were deposited on glass substrates without intentional heating by R-HiPIMS using $500 \mu$ s long pulses. Structural, electrical and optical properties of the AZO films were studied as a function of peak current. Obtained peak power densities are relatively low compared to other metals due to the strong argon gas rarefaction, however, it is possible to increase the peak power density above $0.5 \mathrm{~kW} / \mathrm{cm}^{2}$ by increasing the time between pulses or the average power to reach the HiPIMS regime. If the pulse duration time is $500 \mu \mathrm{s}$, the sustained self-sputtering discharge can be observed when the peak power density is above $0.3 \mathrm{~kW} / \mathrm{cm}^{2}$. The peak current is sensitive to the oxygen content in the sputtering atmosphere so that it can be used as a control parameter for the reactive sputtering. The lowest obtained resistivity of the AZO films is $1.0 \times 10^{-3} \Omega \mathrm{cm}$ with the transmittance around $70 \%$ in the visible light range. From the XRD measurements, there is the indication of existing zincblende structural phase in the RHiPIMS deposited AZO films using high oxygen partial pressure.
\end{abstract}

\section{Introduction}

Aluminium doped zinc oxide (ZnO:Al - AZO) has been investigated and used as a transparent conducting oxide (TCO) already for several decades. Transparent electrodes have many applications in the fields of solar cells, flat panel displays, and low emissivity coatings. The scalability of a deposition technique is a critical part for the large scale production. For this reason the magnetron sputtering is among the most widely used types of deposition [1,2]. Additionally, the implementation of reactive sputtering reduces the production cost due to a lower price of metal targets compared to ceramic targets [3]. Operation in the unstable transition mode as well as the high deposition temperature $\left(>200^{\circ} \mathrm{C}\right.$ ) is necessary to achieve desired properties of AZO thin films in the reactive magnetron sputtering [4,5]. This is the major limitation for the AZO deposition on plastic (flexible) substrates. The elevated deposition temperature is not preferable in the case of CIGS solar cell either [6]. Another drawback of the magnetron sputtering is the negative oxygen ion bombardment of a growing AZO film in front of target axis leading to the non-homogeneity of the film electrical properties $[7,8]$. The bombardment introduces compensation (acceptor) type point defects and/or deactivates $\mathrm{Al}$ dopants.

Pulsed laser deposition (PLD) has been demonstrated as a method to achieve the best AZO properties so far [9]. However, the elevated deposition temperature is still necessary, and the method is not applicable for the large scale deposition. The PLD is characterised by high plasma density, which is also the case in high power impulse magnetron sputtering (HiPIMS). The HiPIMS is a deposition technology in which the power is supplied by high amplitude impulses with a low duty cycle. In the pulse the density of plasma increases up to $10^{20} \mathrm{~m}^{-3}$ leading to the high ionisation of sputtered atoms and near-target process gas due to the short mean free path between collisions [10]. The ionised sputtered atoms can be further utilised in the film growth to control the microstructure of thin film [11]. The additional advantage of the HiPIMS is that the undesirable hysteresis in the reactive sputtering may be reduced (R-HiPIMS) [12,13]. As HiPIMS is already a well-established coating technology in the field of hard coatings, it can become more

\footnotetext{
* Corresponding author.

E-mail address: zubkins@cfi.lu.lv (M. Zubkins).
} 
relevant in the field of TCO deposition in the future.

Only few studies have been published on the AZO deposition by RHiPIMS [14-16], which claim that more homogeneous films and a higher electrical conductivity can be obtained compared to the conventional reactive direct-current magnetron sputtering (R-dcMS). However, it is not clear whether the deposition parameters had been optimised in the case of R-dcMS to make the general conclusion about the benefits of R-HiPIMS, because higher quality AZO films deposited by R-dcMS can be found in other papers [17,18]. Nevertheless, the results are promising and it is reasonable to assume that the R-HiPIMS deposition process can be further improved.

It has been suggested that the better quality films can be obtained even without thermal assistance due to the target surface change during a high power pulse [15]. An oxide layer on the target erosion zone is partly removed during the pulse. This allows more stable operation into the transition zone leading to the slightly substoichiometric compound, especially into the crystalline grains, and reducing the negative oxygen ion bombardment. It is worth mentioning that in the previous studies still relatively low peak power densities were used compared to the common values of the HiPIMS processes. By increasing the peak current or the pulse length the effect of the oxide layer removal should get more pronounced.

In the case of a $\mathrm{Zn}$ target, it is known that the plasma impedance decreases when oxygen is added into the sputtering atmosphere. However, the relative decrease is significantly larger during high power pulses compared to DC sputtering indicating stronger dissociation and ionisation of molecular oxygen [15].

In order to investigate the HiPIMS and R-HiPIMS processes, the current-voltage-time $(C-V-t)$ characteristics during the pulse can be used to gain useful information about the gas rarefaction, the self-sputtering (SS), the gas-recycling etc. The HiPIMS of zinc target is far less studied compared to other metals. Most studies mainly focus on $\mathrm{Ti}, \mathrm{Cr}, \mathrm{Al}, \mathrm{Cu}$ etc. Zinc has 2 to 10 times higher sputtering yield (also SS yield) compared to the previously mentioned metals making it an interesting metal for the HiPIMS process research. In a recent paper [19], where different target materials were sputtered in the same conditions, the HiPIMS discharge was not even reached in the case of high sputter yield metals $(\mathrm{Zn}, \mathrm{Cu}, \mathrm{Ag}$ ) due to high plasma impedance. This raises the question of which sputtering parameters and pulse configurations the actual HiPIMS regime can be obtained to fully exploit the HiPIMS benefits in the thin film deposition. In reactive sputtering the compound layer is formed on the target surface. As there is a difference between metal and compound work functions, the secondary electron emission changes. This leads to the change in peak current, which can then be used as an additional control parameter.

In this paper we study the HiPIMS and R-HiPIMS of $\mathrm{Zn} / \mathrm{Al}$ (98/2 wt $\%$ ) target at different sputtering parameters, such as power, pulse duration time, oxygen flow etc. At every given sputtering condition, the $C$ - $V$ - $t$ characteristics as well as plasma optical emission spectra (OES) were recorded. Only $\mathrm{Zn}$ properties will be taken into account in the interpretation of results, because $\mathrm{Al}$ concentration in the target is only $2.0 \mathrm{wt} \%$. At certain conditions the AZO films were deposited and characterised by XRD, Hall effect and transmittance measurements. As a peak current changes with an oxygen flow rate, the AZO properties were investigated as a function of the peak current. This paper is organised as follows: experimental details, HiPIMS of Zn/Al target, RHiPIMS of $\mathrm{Zn} / \mathrm{Al}$ target, AZO properties, and conclusions.

\section{Experimental details}

The experiments were performed using the vacuum coater G500M/ 2 (Sidrabe). A ION'X ${ }^{\circledast}$ planar, balanced magnetron (Thin Film Consulting) with target dimensions $100 \mathrm{~mm} \times 200 \mathrm{~mm} \times 9 \mathrm{~mm}$ was used. The allowable maximum average power for this magnetron is approximately $4 \mathrm{~kW}$. The power was supplied by a SIP2000USB-10500-D pulse power supply unit (Melec) operating in unipolar negative regime at constant average power. The constant average power regime was selected to prevent target damage and because it was more stable than constant average current or voltage regimes. The maximum output voltage and peak current of this power supply is $1000 \mathrm{~V}$ and $500 \mathrm{~A}$, respectively, thus the maximum pulse power is $500 \mathrm{~kW}$ ( $5 \mathrm{~kW}$ max. DC). The negative voltage was supplied to the magnetron cathode against a grounded anode. The discharge voltage and current were measured by a MS-500-D-TB measuring system (Melec) and recorded by a RIGOL DS1074B digital oscilloscope. The OES from the discharge was collected through the chamber window by an optical fibre probe overlooking the discharge parallel $2 \mathrm{~cm}$ above the target surface. The time-average OES were detected by an Ocean Optics HR4000 spectrometer.

A Zn/Al (98:2 wt\%, purity 99.99\%) alloy target with a thickness of $9 \mathrm{~mm}$ has been sputtered in metallic (Ar) and reactive $\left(\mathrm{Ar}+\mathrm{O}_{2}\right)$ atmospheres. The $C-V$ - $t$ characteristics and OES were studied as a function of pulsing frequency $(25 \mathrm{~Hz}-10 \mathrm{kHz})$, pulse length (100 or $500 \mu \mathrm{s}$, or DC), and average power $(50-500 \mathrm{~W})$. In all cases the pulse voltage was constant for the entire pulse length. The arc detect threshold value was set to $500 \mathrm{~A}$ in the HiPIMS mode. Before the investigation of sputtering process and the AZO film deposition, the chamber $\left(\approx 0.1 \mathrm{~m}^{3}\right)$ was pumped down to base pressure below $1.3 \times 10^{-5}$ mbar by a HiPace 1800 turbo-molecular pump (Pfeiffer) backed with a rotary pump. The $\mathrm{Ar}$ (purity 99.99\%) flow rate of $40 \mathrm{sccm}$ was kept constant in both metallic and reactive modes. The pumping speed was altered by a throttle valve to set the working pressure of $1.0 \times 10^{-2} \mathrm{mbar}$ during the sputtering in pure Ar. In the reactive sputtering, the $\mathrm{O}_{2}(99.5 \%)$ flow rate was varied from 0 to $24 \mathrm{sccm}$, thus the working pressure was in the range of 0.8 to $1.0 \times 10^{-2} \mathrm{mbar}$.

AZO thin films were deposited on soda lime glass substrates by dcMS, pulsed-dcMS and HiPIMS in an $\mathrm{Ar}+\mathrm{O}_{2}$ atmosphere. The glass substrates were ultrasonically cleaned with acetone, detergent, 2-isopropanol for $15 \mathrm{~min}$ each, rinsed with distilled water, and then dried under blown $\mathrm{N}_{2}$ gas. The substrates were not heated intentionally during the deposition process and the distance between the target and the substrate was approximately $11 \mathrm{~cm}$ (a substrate facing the target axis).

The film's thickness was determined by a profilometer, CART Veeco Dektak 150. The AZO structure was examined by an X-ray diffractometer with $\mathrm{Cu} \mathrm{K} \alpha$ radiation, PANalytical XPert Pro. The film's transmittances, in the range of 200 to $1100 \mathrm{~nm}$, were determined by a double-beam spectrophotometer, Analytik Jena AG Specord 210. The electrical resistivity, the carrier concentration and the mobility were measured in the Van der Pauw configuration using a Hall effect system, HMS5000.

\section{Results and discussion}

\section{1. $\mathrm{Zn} / \mathrm{Al}$ sputtering in HiPIMS}

To deposit AZO thin films it was preferable to investigate the $\mathrm{Zn} / \mathrm{Al}$ target sputtering by high power pulses in both metallic and reactive modes. In the beginning, the $\mathrm{Zn} / \mathrm{Al}$ target sputtering in an $\mathrm{Ar}$ atmosphere was gradually changed from a DC to low frequency pulsed regime $(\mathrm{DC}-50 \mathrm{~Hz})$ by increasing the off time between pulses to investigate the pulsing frequency influence on the magnetron discharge. The average power of $300 \mathrm{~W}$ and the pulse duration time of $100 \mu$ s were kept constant. The peak current and the voltage increase when frequency is reduced to maintain the average power (Fig. 1). The sputtering regime reaches the HiPIMS level of $0.5 \mathrm{~kW} / \mathrm{cm}^{2}$ (defined in [20]) at approximately $80 \mathrm{~Hz}$. The current gradually increases during a pulse and reaches the peak current at the end, leading to a triangular profile.

The plasma composition was investigated using OES. The OES spectra recorded $2 \mathrm{~cm}$ above the $\mathrm{Zn} / \mathrm{Al}$ target surface from DC and pulsed-DC (low density) to HiPIMS (high density) discharges are shown in Fig. 2. The plasma emission is dominated by neutral $\mathrm{Ar}$ (Ar I) emission lines with the low intensity lines of neutral $\mathrm{Zn} \mathrm{(Zn} \mathrm{I)} \mathrm{at} \mathrm{the} \mathrm{low}$ 


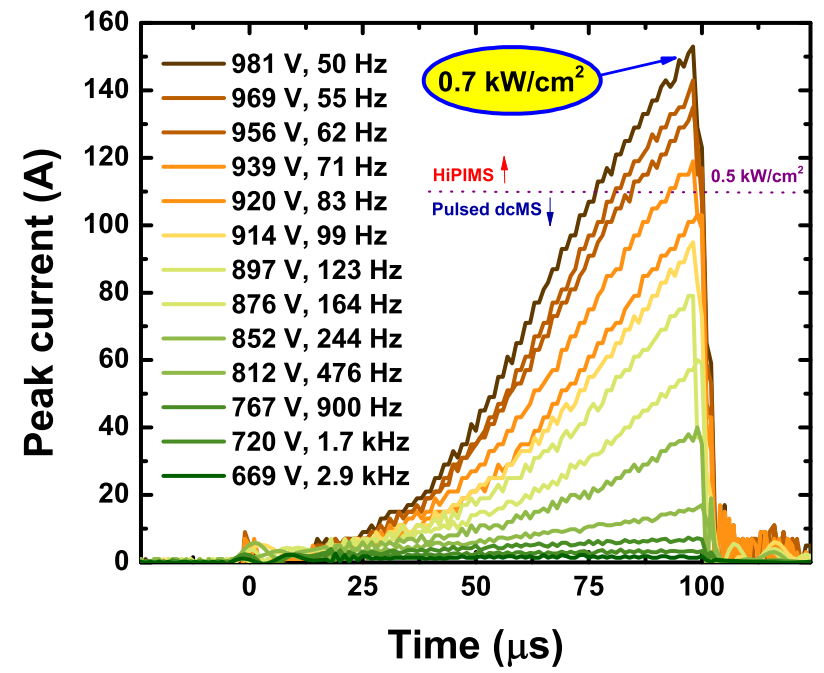

Fig. 1. $C-V-t$ characteristics as a function of frequency during the $\mathrm{Zn} / \mathrm{Al}$ target sputtering in an Ar atmosphere at constant average power mode.

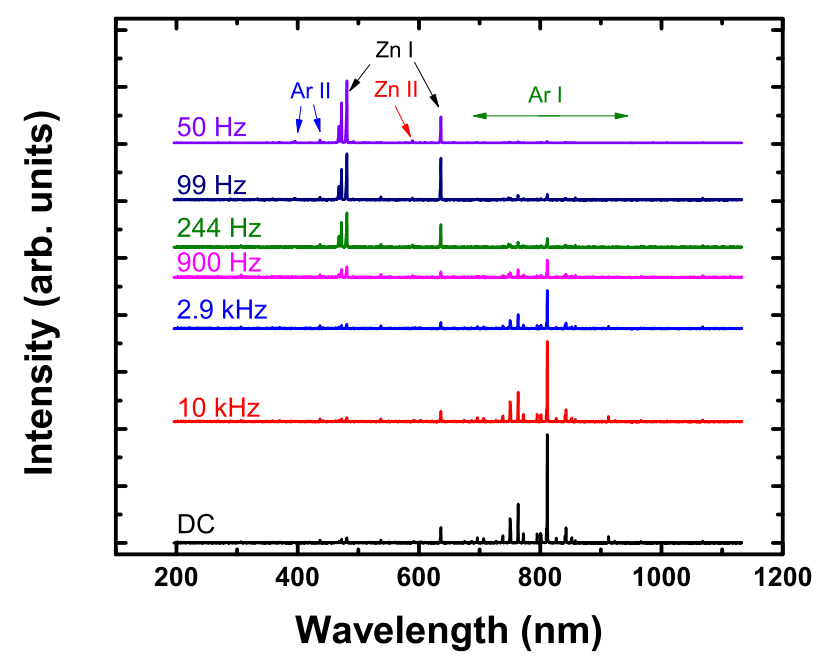

Fig. 2. OES spectra as a function of frequency during the $\mathrm{Zn} / \mathrm{Al}$ target sputtering in an Ar atmosphere at constant average power mode.

density discharge. As the frequency is decreased, the intensity of Ar I lines gradually reduces, whereas the intensity of Zn I increases. At the high-density discharge, the plasma emission spectrum mainly consists of the $\mathrm{Zn} \mathrm{I}$ emission lines. This is the result of significant Ar gas rarefaction by the "sputter wind" [21,22], which is the momentum transfer from sputtered atoms to a process gas. Only low intensity emission lines of either Ar or $\mathrm{Zn}$ ions (Ar II, Zn II) were detected. This is most likely due to the optical fibre focus position because the ion emission is localised closer to the target surface even in the case of $\mathrm{Zn}$ / Al sputtering with unbalanced magnetron [23]. However, Ar ion concentration in the HiPIMS can be low due to the strong Ar rarefaction and the self-sputtering mechanism in the case of a high sputter yield material, like $\mathrm{Zn}(6.2$ at $900 \mathrm{eV} \mathrm{Ar})$. It is reported that the ionisation fraction of sputtered atoms in the case of a $\mathrm{Cu}$ target, which is also a high sputter yield (2.6 at $900 \mathrm{eV} \mathrm{Ar}$ ) material, is around $40 \%$ from the experimental evidence [24] and 27\% from the modelling [25] (peak power density in both cases was approximately $0.5 \mathrm{~kW} / \mathrm{cm}^{2}$ ). It can be predicted that the ionisation fraction in the case of $\mathrm{Zn}$ could be lower because $\mathrm{Zn}$ has higher ionisation energy $(9.4 \mathrm{eV})$ compared to $\mathrm{Cu}$ $(7.7 \mathrm{eV})$ and a lower electron impact ionisation collision cross section [26]. No emission lines of excited or ionised $\mathrm{Al}$ atoms were detected in any of the cases.
Further, to investigate the average sputtering power influence on the plasma discharge it was increased from 50 to $500 \mathrm{~W}$ with the step of $50 \mathrm{~W}$ at two different pulsing configurations $-t_{\mathrm{On}}=100 \mu \mathrm{s}$, $t_{\text {Off }}=10^{\prime} 000 \mu \mathrm{s}, f=99 \mathrm{~Hz}$ and $t_{\text {On }}=500 \mu \mathrm{s}, \quad t_{\text {Off }}=40^{\prime} 000 \mu \mathrm{s}$, $f=25 \mathrm{~Hz}$. The pulse time in the second pulse configuration was increased to allow the discharge to develop into the self-sputtering phase and to detect material dependant features.

The $C-t$ characteristics of the first pulse configuration are shown in Fig. A. 1 in the appendix. The $100 \mu$ s long current profiles are rectangular as before. The peak current grows from $20 \mathrm{~A}\left(0.10 \mathrm{~A} / \mathrm{cm}^{2}\right)$ to 140 A $\left(0.70 \mathrm{~A} / \mathrm{cm}^{2}\right)$ if the voltage is increased from 583 to $967 \mathrm{~V}$. In the magnetron sputtering, the $C-V$ curve follows the power law $I \sim V^{n}$ [27], where the exponent $n$ increases if plasma impedance decreases. In our case the $C-V$ curve exhibits the fracture from $I \sim V^{2}$ to $I \sim V^{8}$ around $850 \mathrm{~V}$ where the peak power density is $0.2 \mathrm{~kW} / \mathrm{cm}^{2}$ (Fig. 3). It can be suggested that at this value the electron density is high enough to strongly enhance the electron impact ionisation of sputtered atoms, thereby reducing the plasma impedance. In the case of dcMS sputtering, the $C$ - $V$ curve obeys the power law of $I \sim V^{4}$. The value of 4 is relatively low compared to conventional dcMS processes [28] suggesting high plasma impedance due to the rarefaction effect.

The $C$ - $t$ characteristics of the second pulse configuration are shown in Fig. 4. Below $780 \mathrm{~V}$, discharge current increases in the initial phase of the pulses $(<250 \mu \mathrm{s})$ and then starts to decrease after the peak current is reached. The production of electrons is faster compared to the recombination and disappearance in the beginning of the pulse [29]. The increase of energetic electrons, which are trapped in the magnetic field near the target surface, favourably affects the process gas ionisation. The impedance of plasma decreases and the discharge current increases in the beginning of the pulse as the concentration of the charge carriers grows. The initial phase of discharge pulse, which is pressure dependant, is dominated by gas ions [30]. The current decrease later in the pulse is strongly related to the rarefaction of inert gas in the vicinity of the target surface. In our case the peak current position shifts from 150 to $250 \mu \mathrm{s}$ if the voltage is increased from 740 to $780 \mathrm{~V}$. The peak current of $12 \mathrm{~A}\left(0.06 \mathrm{~A} / \mathrm{cm}^{2}\right)$ and the peak power density of $0.05 \mathrm{~kW} /$ $\mathrm{cm}^{2}$ at $780 \mathrm{~V}$ is well below the dcMS limit and cannot be considered as HiPIMS.

When the voltage is increased by only $10 \mathrm{~V}$ from 780 to $790 \mathrm{~V}$, the $C$-t characteristic changes significantly in the later phase of the pulse indicating a new process that compensates the current decrease. The sputtered atoms and ions start to strongly affect the discharge. The

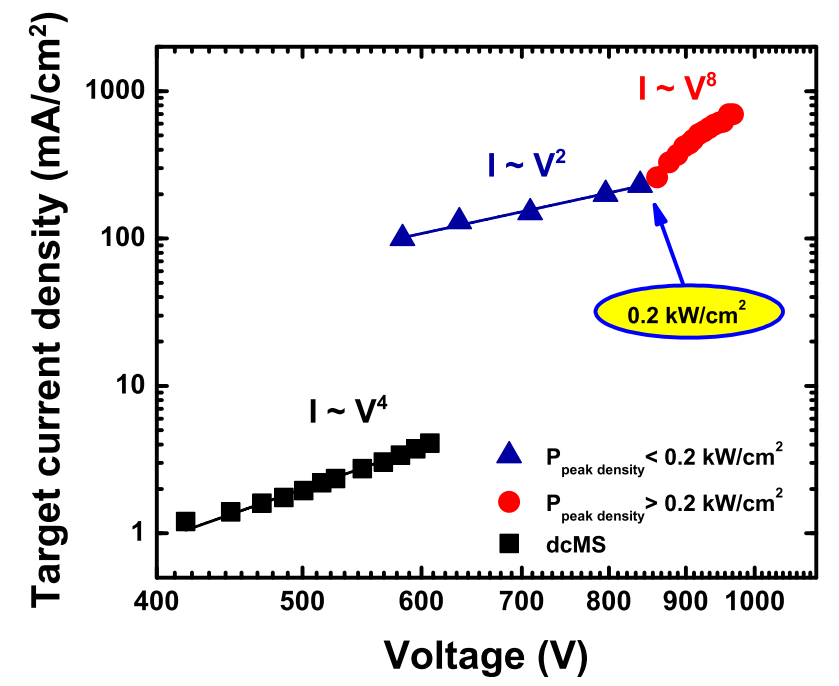

Fig. 3. $C$ - $V$ curves for the pulsed sputtering $\left(t_{\mathrm{On}}=100 \mu \mathrm{s}, t_{\mathrm{Off}}=10^{\prime} 000 \mu \mathrm{s}\right)$ and dcMS. In the case of pulsed sputtering the target current density refers to the pulse current. 


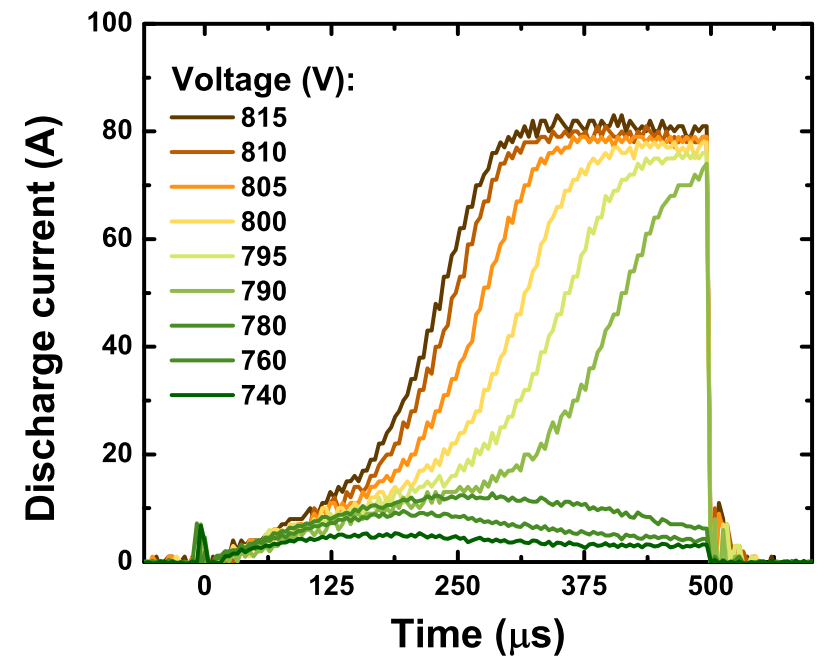

Fig. 4. $C$ - $V$ - $t$ characteristics with the pulse time of $500 \mu$ s plotted for different applied average power.

plasma impedance decreases sharply in the end of the pulse and the current reaches the value of $73 \mathrm{~A}\left(0.37 \mathrm{~A} / \mathrm{cm}^{2}\right)$ at $790 \mathrm{~V}$. The corresponding peak power density of $0.3 \mathrm{~kW} / \mathrm{cm}^{2}$ is above dcMS limit and indicates the HiPIMS. In the HiPIMS, additionally to the primary ions of inert gas (ionised for the first time), the recycled ions of sputtered atoms and inert gas should be considered. The generalised recycling model (GRM) [31] reveals that above the critical current density (in our case, approximately $0.2 \mathrm{~A} / \mathrm{cm}^{2}$ ) either gas or self-sputter (SS) recycling is necessary to carry the current. In general, the inert gas ions are predominant in the beginning of the pulse and partly replaced by the target material ions during the pulse [30]. In the case of materials with a high self-sputter yield $\left(\mathrm{Y}_{\mathrm{SS}}\right)$, SS-recycling is dominating over the gas recycling [32] leading to the sustained self-sputtering (SSS). The $\mathrm{Y}_{\mathrm{SS}}>1$ is necessary to satisfy the condition for the SSS [10]:

$\Pi=\alpha \beta Y_{S S} \geq 1$

where $\alpha$ is the ionisation probability of a sputtered atom and $\beta$ is the probability that the ion will return to the target. However, the condition $\mathrm{Y}_{\mathrm{SS}}>1$ is not sufficient for the SSS. In our case it can be concluded that when the peak power density is increased above $0.05 \mathrm{~kW} / \mathrm{cm}^{2}$, the parameter $\Pi$ in (1) exceeds unity and SS runaway occurs. In other words, the plasma density reaches a threshold to strongly enhance the ionisation of sputtered $\mathrm{Zn}$ atoms and the SSS is accomplished.

If the voltage is increased even further, the sputtered atom ionisation and the SS recycling start earlier because all involved processes are driven at a greater rate. The peak current develops faster, and the $C$-t profile gets wider with a plateau current. The peak current value increases only slightly up to $81 \mathrm{~A}\left(0.4 \mathrm{~A} / \mathrm{cm}^{2}\right)$ at $815 \mathrm{~V}$ (Fig. 5). The plateau current indicates a new steady state in which the composition balance is achieved and $\Pi$ in (1) is equal to unity if the SSS phase is accomplished only by the $\mathrm{Zn}$ ions, or is slightly lower if the Ar ions also contribute [33]. Double charged Zn ions should be present in the discharge to maintain the SSS phase because single charged ions cannot produce enough secondary electrons, which are highly important for the ionisation process. It should be possible because the ionisation energy to obtain double charge $\mathrm{Zn}$ ions $(18.0 \mathrm{eV})$ is just slightly greater than the ionisation energy of neutral Ar $(15.8 \mathrm{eV})$. Additionally, in the case of high SS yield material like Zn, the SSS phase can be maintained with a moderate degree of ionisation and relatively low concentration of double charged ions [34]. However, it is notable that the current decreases slightly during the plateau (Fig. 4). The decrease indicates that no highly charged $\mathrm{Zn}$ ions are produced according to Wu et al. [29]. The obtained plateau current densities are relatively low compared to other metals in the SSS phase. This is because of the lower

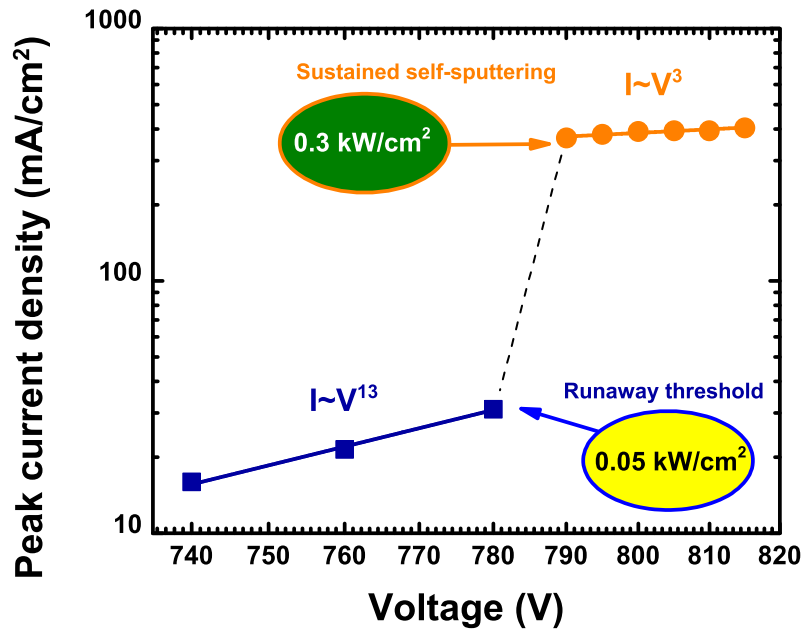

Fig. 5. $C-V$ curves in the case of pulsed $\left(t_{\text {On }}=500 \mu s, t_{\text {Off }}=40^{\prime} 000 \mu s\right)$ sputtering.

primary current of Ar ions that are ionised for the first time and act as a seed for the recycling processes. It is shown that the minimum steady state current to maintain the SSS phase decreases when the rarefaction is more pronounced [35].

The optical plasma emission spectra were recorded at every set voltage. The spectra in Fig. A.2 mainly consist of excited $\mathrm{Zn}$ atom lines (468.0, 472.2, 481.1, 636.2 nm). In the spectra, there is a low intensity emission line at $589.4 \mathrm{~nm}$ corresponding to single charged zinc ions. The intensity of the excited and single charged $\mathrm{Zn}$ emission lines as a function of voltage is shown in Fig. A.3. The intensity of both lines sharply increases between 780 and $800 \mathrm{~V}$. Above $800 \mathrm{~V}$ the steepness of the intensity increase reduces. There is a good correlation between the intensity of lines and the peak current density.

\subsection{Reactive $\mathrm{Zn} / \mathrm{Al}$ sputtering (R-HiPIMS)}

The reactive HiPIMS process was studied again using two different pulsing configurations $-t_{\mathrm{On}}=100 \mu \mathrm{s}, t_{\mathrm{Off}}=10^{\prime} 000 \mu \mathrm{s}, f=99 \mathrm{~Hz}$ and $t_{\text {On }}=500 \mu \mathrm{s}, t_{\text {Off }}=40^{\prime} 000 \mu \mathrm{s}, f=25 \mathrm{~Hz}$. The average power of $300 \mathrm{~W}$ was kept constant. The two pulsing configurations were selected so that the peak power density at the given average power value is relatively high ( 0.5 and $0.3 \mathrm{~kW} / \mathrm{cm}^{2}$, respectively) before the oxygen introduction. The $C$ - $t$ characteristics of the first pulsing configuration as a function of oxygen flow rate are shown in Fig. 6. The oxidation of target surface elevates the secondary electron emission (SEE) in the case of $\mathrm{Zn} / \mathrm{Al}$ target. This is the reason why the current increases faster and reaches a higher peak value when the oxygen flow is increased. However, there are no large changes in the $C$ - $t$ characteristics in terms of shape and peak value.

Further AZO films were deposited at three different sputtering regimes: (1) DC; (2) $t_{\mathrm{On}}=100 \mu \mathrm{s}, t_{\mathrm{Off}}=1^{\prime} 000 \mu \mathrm{s}, f=909 \mathrm{~Hz}$; and (3) $t_{\text {On }}=100 \mu \mathrm{s}, t_{\text {Off }}=10^{\prime} 000 \mu \mathrm{s}, f=99 \mathrm{~Hz}$. It can be seen in Fig. 7 that a higher oxygen flow rate is necessary to reach a transition mode and achieve transparent films when the frequency is decreased. In the dcMS, there is a balance between the formation and removal of the oxide layer on the target surface when operating in the transition mode. The removal of compound molecules is proportional to the ion target current density [20]. In the HiPIMS, discharge peak current density changes during a pulse and reaches a very high value. This leads to the high and inconsistent sputtering rate during the pulse time. If the oxide layer is removed from the target surface in the initial stage of the pulse, the sputtering rate sharply increases later in the pulse, which means that a higher oxygen flow rate is necessary to form a stoichiometric compound film. This might be the reason why a higher oxygen flow is necessary to produce transparent AZO films when frequency is reduced, thus the 


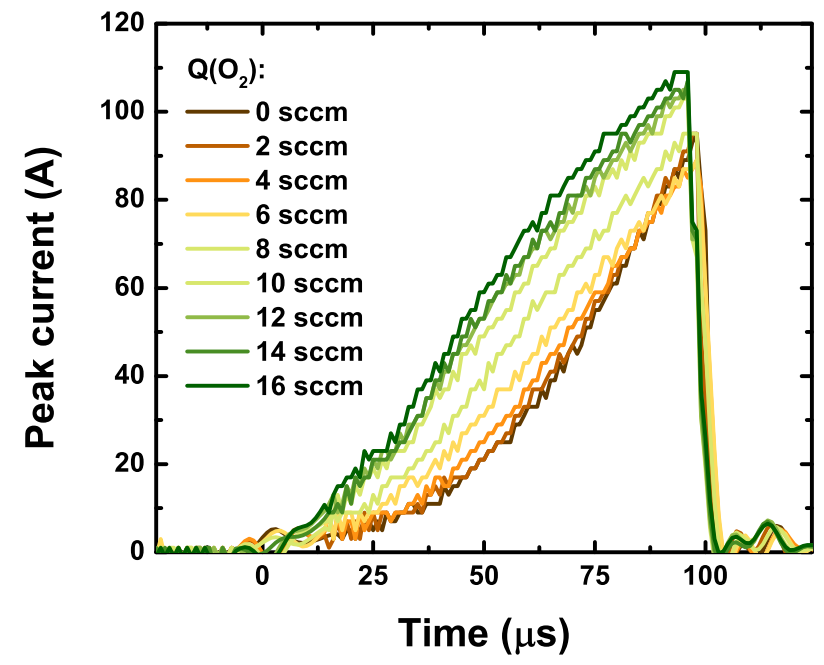

Fig. 6. $C-t$ characteristics as a function of oxygen flow rate when the pulse duration time is $100 \mu \mathrm{s}$.

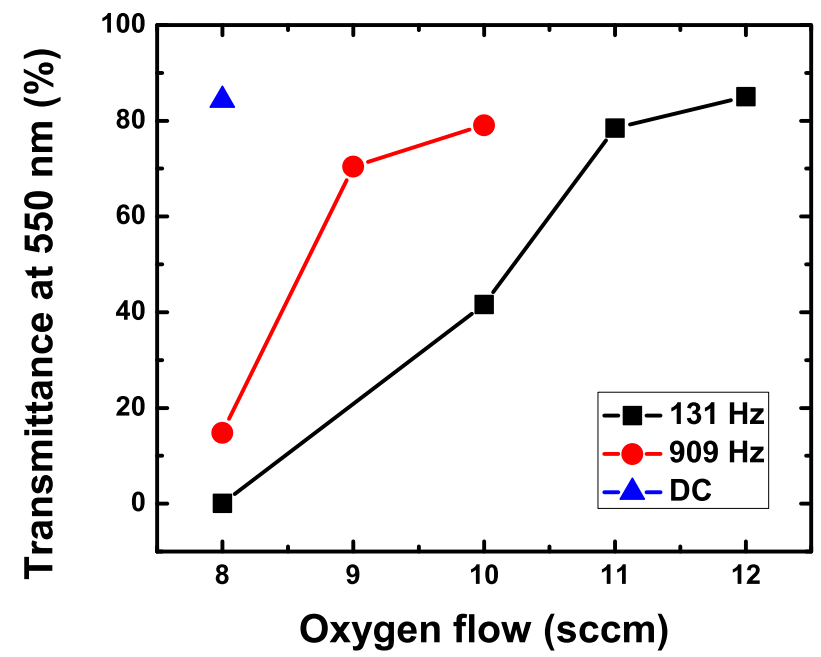

Fig. 7. Transmittance at $550 \mathrm{~nm}$ of the AZO films as a function of oxygen flow at different sputtering regimes: $(131 \mathrm{~Hz}) t_{\mathrm{On}}=100 \mu \mathrm{s}, t_{\mathrm{Off}}=7^{\prime} 500 \mu \mathrm{s} ;(909 \mathrm{~Hz})$ $t_{\mathrm{On}}=100 \mu \mathrm{s}, t_{\mathrm{Off}}=1^{\prime} 000 \mu \mathrm{s}$; and (DC). All the films were deposited at pressure of approximately $0.01 \mathrm{mbar}$ and at average power of $300 \mathrm{~W}$.

peak current density is increased. Additionally, the formation of an oxide layer between HiPIMS pulses is reduced due to rarefaction of the oxygen gas [36].

The deposition rate of the AZO films in the transition mode decreases when the sputtering mode approaches the HiPIMS (Fig. 8). Most likely it is because a part of the sputtered $\mathrm{Zn}$ atoms are ionised close to the target and attracted back by the negative target potential [37]. SS yields for various target materials are typically 10-15\% lower compared to the yields of Ar ion sputtering [38]. That is why it is reasonable to decrease the pulse time to not allow the gas rarefaction and the SS to develop further if the higher deposition rate is necessary. In the case of $\mathrm{Zn}$, the SS yield in the projectile energy range from 300 to $800 \mathrm{eV}$ is from 15 to $20 \%$ higher compared to the Ar ion-sputtering yield [39]. However, in the SS the projectile is lost, which reduces the sputtering yield by 1 [20]. Additionally, the secondary electron emission decreases in the SS mode. All these effects reduce the overall deposition rate. If we compare deposition rates of $100 \mu$ s (Fig. 8) and $500 \mu$ s (Table 1) long pulses, then the deposition rate is higher in the case of $500 \mu \mathrm{s}$. It is worth mentioning that it is not completely correct to compare dcMS and HiPIMS deposition rates at the same average power because the non-linear scaling coefficient of the sputter yield with the applied

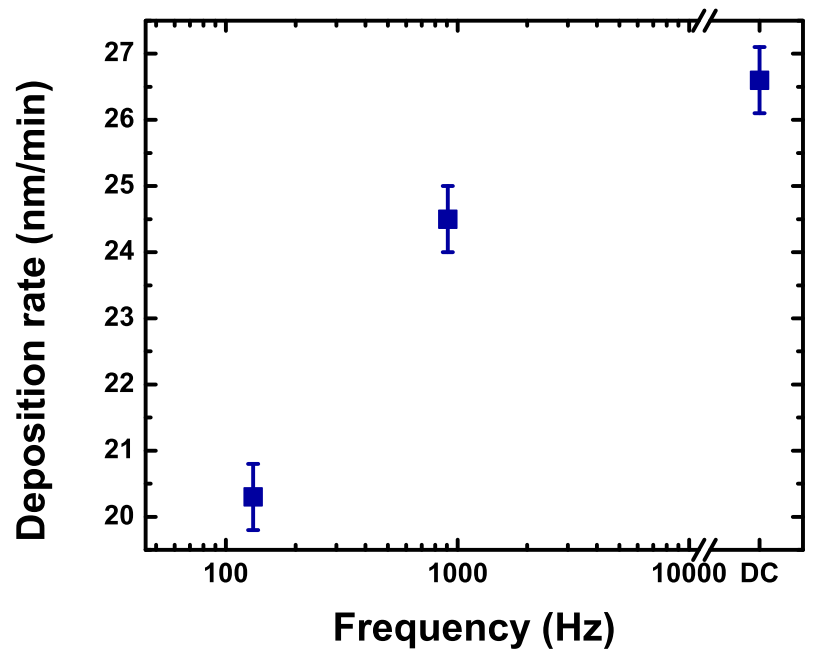

Fig. 8. Deposition rates in the transition mode for the different sputtering frequencies $\quad\left(131 \mathrm{~Hz}: t_{\mathrm{On}}=100 \mu \mathrm{s}, t_{\mathrm{Off}}=7^{\prime} 500 \mu \mathrm{s} ; \quad 909 \mathrm{~Hz}: t_{\mathrm{On}}=100 \mu \mathrm{s}\right.$, $t_{\mathrm{Off}}=1^{\prime} 000 \mu \mathrm{s}$; and DC) with the constant average power of $300 \mathrm{~W}$.

voltage should be taken into account. The lower deposition rate of the HiPIMS compared to the dcMS seems to be solved by advantage magnet arrangement in the magnetron (known as "TriPack" magnetron [40]) and by using a positive pulse after a negative one (known as "positive kick" [41]).

In the second pulsing configuration, the $C-t$ characteristics changed significantly when the oxygen flow rate was introduced (Fig. 9). The current starts to decrease in the end of the pulse, and at the same time the steepness of the $C-t$ profile starts to increase in the initial phase of the pulse when oxygen is gradually increased from 0 to $16 \mathrm{sccm}$. As the oxygen content in the sputter atmosphere is increased, the $\mathrm{Zn} / \mathrm{Al}$ target surface gets more poisoned. As a result the sputter yield decreases. In this case it is expected that the self-sputtering contribution reduces and gas recycling gets more pronounced. However, from our experiments it is not possible to distinguish the argon, oxygen and zinc ion contributions during the pulse. The changes in the sputter yield and the SEE allow the discharge current to reach the maximum value earlier in the pulse. It is shown in the case of $\mathrm{Ti}$ that in the poisoned mode the Ar ion contribution to the discharge current is the most significant, with the small contribution of oxygen and titanium ions in the end of the pulse [31]. As the $C$ - $t$ characteristic is sensitive to the oxygen flow rate, it seems that it can be used to determine the target surface state and control the reactive sputtering process.

\subsection{Characterisation of the AZO films}

The structure and the optical and electrical properties were studied for the DC and HiPIMS ( $t_{\text {On }}=500 \mu \mathrm{s}, t_{\text {Off }}=40^{\prime} 000 \mu \mathrm{s}$ ) deposited AZO films listed in Table 1 . Note that, when the oxygen flow rate was increased from 20 to $22 \mathrm{sccm}$, the other deposition parameters as well as the deposition rate behave in reverse to the previous behaviour, indicating that an oxygen flow is not a reliable deposition control parameter. Since the peak current is sensitive to the oxygen content in the sputtering atmosphere, the structure and the properties of the films were studied as a function of the peak current. The deposition modes (metal, transition or oxide) in Table 1. were approximately determined from the transmittance and the Hall effect measurements.

\subsubsection{XRD measurements}

The evolution of the X-ray diffractograms as a function of peak current for the DC and HiPIMS deposited AZO films is shown in Fig. 10. A significant diffraction maximum, which corresponds to the (002) plane, was observed at around $34^{\circ}$ for the DC and HiPIMS deposited 
Table 1

Deposition parameters, thicknesses and deposition rates of the AZO samples.

\begin{tabular}{|c|c|c|c|c|c|c|c|}
\hline Deposition mode & $\begin{array}{l}\text { Oxygen flow } \\
\text { (sccm) }\end{array}$ & $\begin{array}{l}\text { Work pressure } \\
\text { (mTorr) }\end{array}$ & Voltage (V) & $\begin{array}{l}\text { Peak current } \\
\text { (A) }\end{array}$ & $\begin{array}{l}\text { Emission line intensity ratio I } \\
\left(\mathrm{O}_{777}\right) / \mathrm{I}\left(\mathrm{Zn}_{636}\right)\end{array}$ & Thickness (nm) & $\begin{array}{l}\text { Deposition rate }(\mathrm{nm} / \\
\text { min) }\end{array}$ \\
\hline DC (transition) & 8 & 6.8 & 377 & - & 0.070 & 266 & 27 \\
\hline HiPIMS (metal) & 10 & 6.6 & 670 & 50 & 0.026 & 1383 & 92 \\
\hline HiPIMS (metal) & 14 & 7.0 & 594 & 60 & 0.035 & 1255 & 84 \\
\hline HiPIMS (metal/trans.) & 16 & 7.2 & 581 & 65 & 0.048 & 1190 & 79 \\
\hline HiPIMS (metal/trans.) & 18 & 7.4 & 570 & 70 & 0.058 & 1113 & 74 \\
\hline HiPIMS (transition) & 20 & 7.5 & 540 & 80 & 0.080 & 484 & 32 \\
\hline HiPIMS (metal/trans.) & 21 & 7.5 & 556 & 73 & 0.069 & 296 & 49 \\
\hline HiPIMS (transition) & 22 & 7.6 & 545 & 75 & 0.084 & 221 & 37 \\
\hline HiPIMS (transition) & 23 & 7.7 & 533 & 80 & 0.107 & 488 & 31 \\
\hline HiPIMS (trans./oxide) & 24 & 7.8 & 513 & 85 & 0.140 & 403 & 27 \\
\hline
\end{tabular}

Constant deposition parameters: average sputtering power of $300 \mathrm{~W}$ and Ar flow rate of $40 \mathrm{sccm}$.

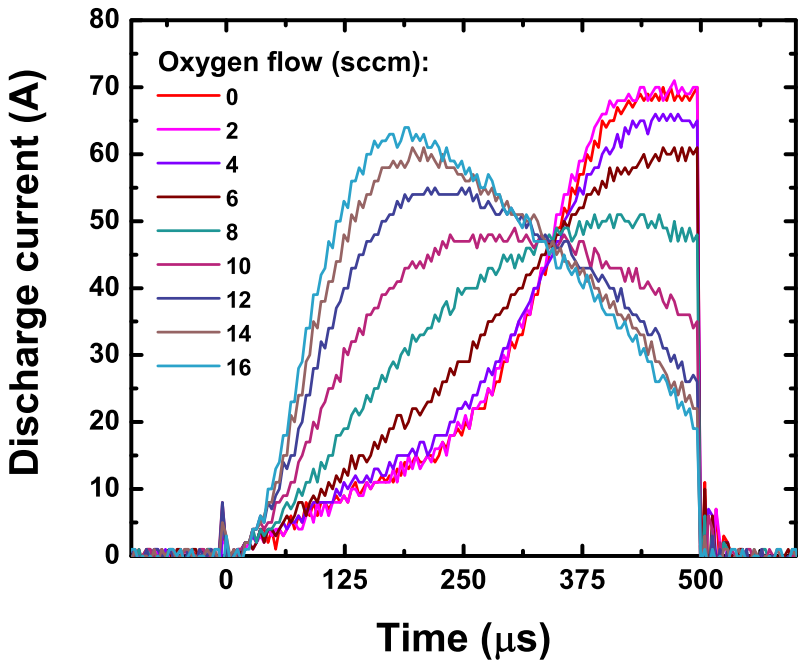

Fig. 9. $C$ - $t$ characteristics as a function of oxygen flow rate when the pulse duration time is $500 \mu \mathrm{s}$.

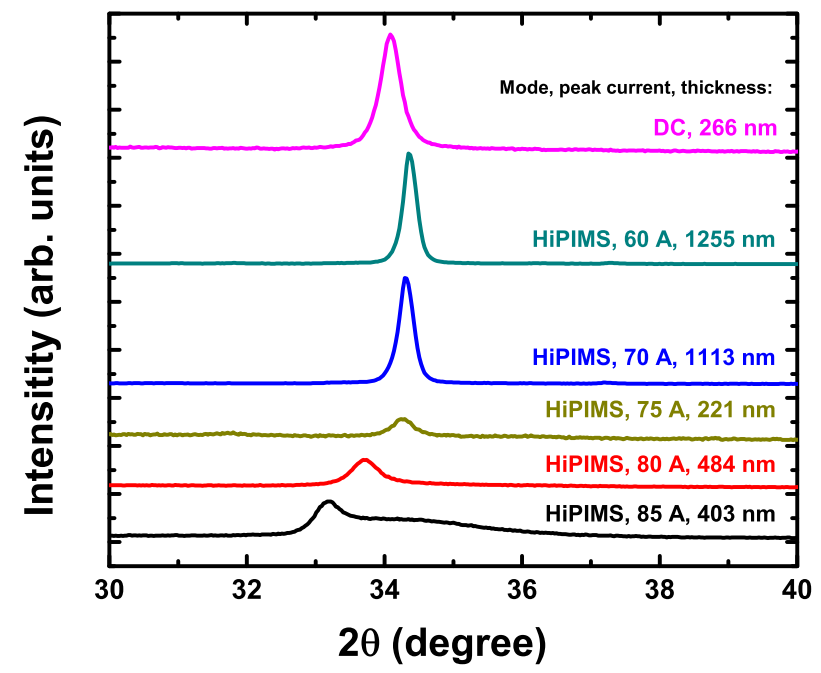

Fig. 10. X-ray diffractograms of the DC and HiPIMS $\left(t_{\mathrm{On}}=500 \mu \mathrm{s}\right.$, $t_{\text {Off }}=40^{\prime} 000 \mu \mathrm{s}$ ) deposited AZO films as a function of peak current. All the films were deposited at pressure of approximately $0.01 \mathrm{mbar}$ and at average power of $300 \mathrm{~W}$.

AZO films, indicating that the films contain a crystalline phase growing preferentially with the $c$-axis of the wurtzite-type $\mathrm{ZnO}(\mathrm{w}$ - $\mathrm{ZnO})$ lattice perpendicular to the glass substrate surface. None of the case phases of $\mathrm{Zn}, \mathrm{Al}_{2} \mathrm{O}_{3}$ or $\mathrm{ZnAl}_{2} \mathrm{O}_{4}$ were detected.
In the case of the HiPIMS deposited films, the diffraction angle of the (002) maximum sharply shifts from $34.3^{\circ}$ to $33.2^{\circ}$ when the peak current is increased from 75 to $85 \mathrm{~A}$. The large shift suggests a new structural phase. However, in the case of the AZO film at 85 A peak current, the main maximum has a shoulder in the direction of higher angles suggesting a still existing $\mathrm{w}$-ZnO phase. It is hard to identify a structural phase from only one XRD maximum. The reference X-ray diffractograms of different $\mathrm{ZnO}$ structural phases, such as zincblende and rocksalt, $\mathrm{ZnAl}_{2} \mathrm{O}_{4}$ spinel, and $\mathrm{ZnO}_{2}$ pyrite are shown in Fig. A.4. Among all the phases only zincblende exhibits the diffraction maximum of (111) plane at $33.5^{\circ}$, which is close to $33.2^{\circ}$. It can be concluded that there is the indication of existing zincblende phase in the AZO films deposited by the HiPIMS together with high oxygen content in the sputtering atmosphere.

Comparing the X-ray diffractograms between the HiPIMS and DC deposited films in the transition mode with similar thicknesses (samples: (1) DC; (2) HiPIMS, 75 A; in Fig. 10), the intensity of the (002) maximum is less in the case of the HiPIMS deposited film. However, the crystalline size in the [002] direction calculated by the Scherrer equation for the DC and HiPIMS deposited films are similar -32 and $29 \mathrm{~nm}$, respectively. Furthermore, the lattice parameter $c$ of $5.23 \AA$ for the HiPIMS deposited film is closer to the $\mathrm{w}-\mathrm{ZnO}$ crystal parameter ( $c=5.21 \AA$ ) compared to the $c$ of $5.26 \AA$ for the DC deposited film.

\subsubsection{Electrical properties}

The electrical resistivity, the charge carrier concentration and the Hall mobility of the HiPIMS deposited AZO films were measured at a temperature of $300 \mathrm{~K}$ and are shown in Fig. 11. The sign of the Hall coefficient of all measured samples was negative, indicating $n$-type conductivity and free electrons in the conduction band as charge carriers. There is no Hall effect measurement data for the sample at $85 \mathrm{~A}$ because the Hall voltage was not large enough to be accurately measured. Relatively high electrical conductivity was achieved in the peak current range from 60 to $70 \mathrm{~A}$. The minimum obtained resistivity was $1.0 \times 10^{-3} \Omega \mathrm{cm}$ with the electron concentration of $5.3 \times 10^{20} \mathrm{~cm}^{-3}$ and the mobility of $11.8 \mathrm{~cm}^{2} \mathrm{~V}^{-1} \mathrm{~s}^{-1}$ at $65 \mathrm{~A}$. The resistivity grows if the peak current is either increased or decreased due to the mobility decrease. The resistivity of the DC deposited AZO film in the transition mode was $3.8 \times 10^{-2} \Omega \mathrm{cm}$ with the electron concentration of $5.4 \times 10^{19} \mathrm{~cm}^{-3}$ and the mobility of $3.0 \mathrm{~cm}^{2} \mathrm{~V}^{-1} \mathrm{~s}^{-1}$.

At a low peak current, a highly substoichiometric compound with a large number of intrinsic point defects forms due to the low oxygen content in the sputtering atmosphere. This raises the free electron concentration and reduces the visible light transmittance. When oxygen content grows, the electron concentration accordingly decreases. The highly transparent films were obtained above $75 \mathrm{~A}$ (Section 3.3.3). The film deposited at $75 \mathrm{~A}$ already exhibits for the TCO standards low free electron concentration of $1.4 \times 10^{20} \mathrm{~cm}^{-3}$. This indicates rather low $\mathrm{Al}$ dopant activation. $\mathrm{Al}$ impurities must replace $\mathrm{Zn}$ ions in the $\mathrm{ZnO}$ crystal lattice to be an effective electron donor. In that case, one additional 


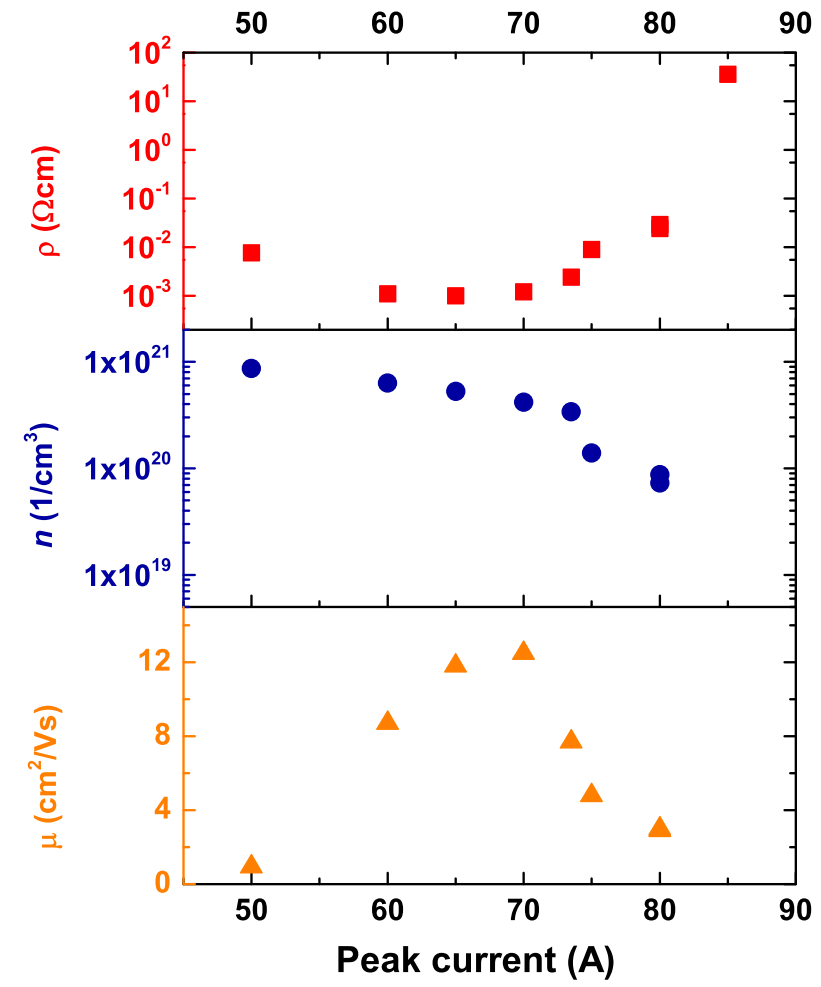

Fig. 11. Resistivity, electron concentration and mobility of the HiPIMS $\left(t_{\mathrm{On}}=500 \mu \mathrm{s}, t_{\mathrm{Off}}=40^{\prime} 000 \mu \mathrm{s}\right)$ deposited AZO films as a function of peak current. All the films were deposited at pressure of approximately $0.01 \mathrm{mbar}$ and at average power of $300 \mathrm{~W}$.

electron from the shallow donor level could be excited in the conductive band. As the $\mathrm{Al}$ concentration can differ between the target and the deposited films and has not been directly measured, the value of the activation cannot be presented here.

The decrease of electron concentration at higher oxygen flow values is caused by either the oxidation of $\mathrm{Al}$ impurities $\left(\mathrm{Al}_{2} \mathrm{O}_{3}\right)$ or the formation of homologous phase that prevents good dopant activation. In the case of the oxidation, $\mathrm{Al}$ dopants no longer perform as donor-type defects [42]. The increase of oxygen content also reduces the concentration of interstitial zinc defects, which are native donor-type defects in $\mathrm{ZnO}$. At higher oxygen flow values, the formation of zinc vacancies and interstitial oxygens, which could act as acceptor-type defects, is also possible [43].

The mobility of the HiPIMS deposited AZO films crosses the maximum value of $12.5 \mathrm{~cm}^{2} \mathrm{~V}^{-1} \mathrm{~s}^{-1}$ at $70 \mathrm{~A}$ when the peak current is increased from 50 to $80 \mathrm{~A}$. Scattering mechanisms must be considered to interpret the effect of peak current on electron mobility. In polycrystalline $\mathrm{ZnO}$, the grain barrier scattering dominates if the electron concentration is in the range approximately from $1 \times 10^{18}$ to $2 \times 10^{20} \mathrm{~cm}^{-3}$ [44]. Above $2 \times 10^{20} \mathrm{~cm}^{-3}$, the contribution of the grain barrier scattering gradually decreases, as the potential barrier height on the grain boundaries reduces, and the contribution of the ionised impurity scattering increases.

Since the films are highly substoichiometric at low peak currents, they contain a lot of point defects that cause the lower mobility. When the oxygen content is increased, the composition becomes more homogenous and the mobility increases. Later the mobility decreases because the potential barrier height on the grain boundaries grows as the electron concentration decreases. The maximum obtained mobility of $12.5 \mathrm{~cm}^{2} \mathrm{~V}^{-1} \mathrm{~s}^{-1}$ is approximately four times smaller than the theoretically obtainable [5], indicating that the crystallinity is not high enough due to the low deposition temperature.

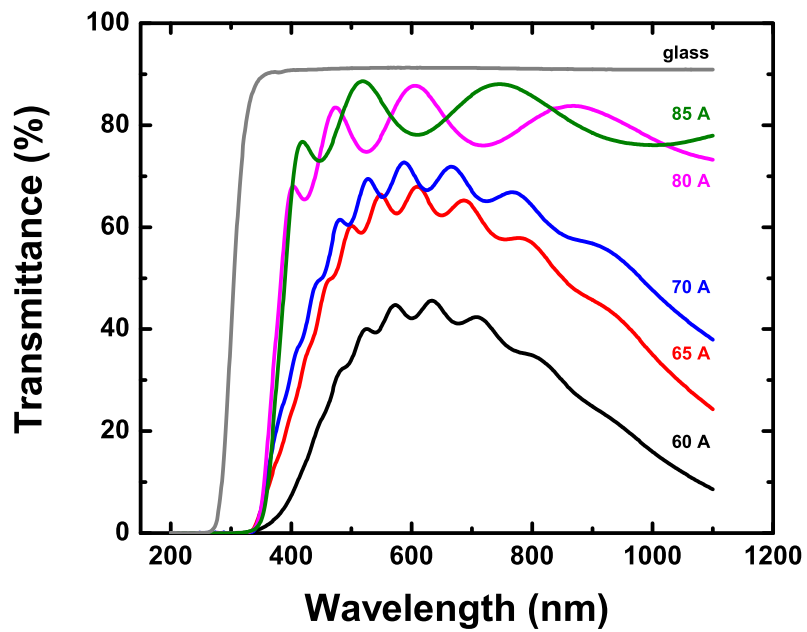

Fig. 12. Transmittance of the HiPIMS $\left(t_{\mathrm{On}}=500 \mu \mathrm{s}, t_{\mathrm{Off}}=40^{\prime} 000 \mu \mathrm{s}\right)$ deposited AZO films in the range of 200 to $1100 \mathrm{~nm}$ as a function of peak current. All the films were deposited at pressure of approximately 0.01 mbar and at average power of $300 \mathrm{~W}$. The reference was measured with an uncoated glass substrate.

\subsubsection{Optical transmittance}

The transmittance of the HiPIMS deposited AZO films on glass was measured in the range of 200 to $1100 \mathrm{~nm}$. The transmittance at $550 \mathrm{~nm}$ grows from 40 to $80 \%$ if the peak current is increased from 60 to $85 \%$ (Fig. 12). It is again explainable by the fact that at low peak currents, a highly substoichiometric compound with the high concentration of free electrons forms. The optical band gap $\left(E_{g}\right)$ was estimated from the fundamental absorption edge by applying the Tauc model [45]. The optical band gap of the films shifts from 3.65 to $3.50 \mathrm{eV}$ when the peak current is increased from 65 to $85 \mathrm{~A}$ as the electron concentration decreases from 5.3 to $0.73 \times 10^{20} \mathrm{~cm}^{-3}$, which is known as Burtein-Moss effect [46].

\subsubsection{Figure of merit}

The performance of the deposited AZO films was estimated using the figure of merit of Haacke $\left(T^{10} / R_{\text {sheet }}\right)$ [47]. The obtained properties are moderate compared to the best AZO films deposited in other studies (Table 2). The deposited film at $65 \mathrm{~A}$ exhibits the highest figure of merit value of $8 \times 10^{-4} \Omega^{-1}$. In the particular case, it was not possible to achieve low resistivity and high visible light transmittance simultaneously. There can be several reasons for that. First of all, the depositions were performed without any feedback control that could ensure a stable process in the transition zone. We can also argue that the target composition and/or the substrate position against the target were not optimal. In this study, the R-HiPIMS discharge reached the SS mode during the pulse. We can therefore conclude that the SS might not be an ideal mode for the AZO deposition.

\section{Conclusions}

The $C$ - $V$ - $t$ characteristics and plasma OES of the metallic (Ar) and reactive $\left(\mathrm{Ar}+\mathrm{O}_{2}\right.$ ) HiPIMS of $\mathrm{Zn} / \mathrm{Al}$ target have been studied. Due to the high sputter yield of $\mathrm{Zn}$, strong Ar gas rarefaction has been observed and lower peak power densities compared to other metals were obtained. Nevertheless, the HiPIMS regime can be achieved by increasing the time between pulses or increasing the average power. When the peak power density of $500 \mu$ s pulses is above $0.3 \mathrm{~kW} / \mathrm{cm}^{2}$, the sustained self-sputtering discharge develops.

The AZO films have been deposited by R-HiPIMS without intentional heating during deposition and studied as a function of peak current. The changes in electrical and optical properties showed that the peak current can be used as a control parameter in the reactive sputtering. A higher oxygen flow rate is necessary to achieve 
Table 2

Figures of merit of AZO films from existing literature.a

\begin{tabular}{|c|c|c|c|c|}
\hline Method & Substrate temperature $\left({ }^{\circ} \mathrm{C}\right)$ & Target & Figure of merit by Haacke [47] $\left(\mathrm{Ohm}^{-1}\right)^{\mathrm{a}}$ & Reference \\
\hline R-HiPIMS & $\mathrm{RT}$ & $\mathrm{Zn} / \mathrm{Al} 2.0 \mathrm{wt} \%$ & 0.0008 & This study \\
\hline R-HiPIMS & RT & $\mathrm{Zn} / \mathrm{Al} 1.5 \mathrm{wt} \%$ & 0.0017 & [12] \\
\hline R-HiPIMS & RT & $\mathrm{Zn} / \mathrm{Al} 1.3 \mathrm{wt} \%$ & 0.0042 & [13] \\
\hline R-HiPIMS & 200 & $\mathrm{Zn} / \mathrm{Al} 1.5 \mathrm{wt} \%$ & 0.0235 & [12] \\
\hline R-HiPIMS & 600 & $\mathrm{Zn} / \mathrm{Al} 0.8 \mathrm{wt} \%$ & 0.0176 & [14] \\
\hline R-dcMS & RT & $\mathrm{Zn} / \mathrm{Al} 2.0 \mathrm{wt} \%$ & 0.0219 & [17] \\
\hline R-dcMS & 290 & $\mathrm{Zn} / \mathrm{Al} 1.0 \mathrm{wt} \%$ & 0.0281 & [18] \\
\hline
\end{tabular}

a These are approximate values of figure of merit because the precise data of either sheet resistance or transmittance were not available in all cases.

transparent AZO films by R-HiPIMS compared to R-dcMS. A slight improvement in electrical conductivity was achieved when depositing AZO films at low temperature by R-HiPIMS; however, the film properties are still moderate suggesting that the SS is not an optimal mode to achieve high quality AZO films. From the XRD, there is the indication of existing zincblende structural phase in the AZO films deposited at high oxygen partial pressure. However, further research is necessary to prove this fact.

\section{Acknowledgments}

Financial support provided by Scientific Research Project for Students and Young Researchers Nr. SJZ/2017/4 realised at the Institute of Solid State Physics, University of Latvia is greatly acknowledged.

\section{References}

[1] J. Gao, K. Kempa, M. Giersig, E.M. Akinoglu, B. Han, R. Li, Physics of transparent conductors, Adv. Phys. 65 (6) (2016) 553-617, https://doi.org/10.1080/ 00018732.2016 .1226804$.

[2] G. Bräuer, Large area glass coating, Surf. Coat. Technol. 112 (1-3) (1999) 358-365, https://doi.org/10.1016/S0257-8972(98)00737-3.

[3] K. Ellmer, Magnetron sputtering of transparent conductive zinc oxide: relation between the sputtering parameters and the electronic properties, J. Phys. D. Appl. Phys. 33 (4) (2000) R17, https://doi.org/10.1088/0022-3727/33/4/201.

[4] M. Zubkins, R. Kalendarev, K. Vilnis, A. Azens, J. Purans, Structural, electrical and optical characteristics of Al-doped zinc oxide thin films deposited by reactive magnetron sputtering, IOP Conference Series: Materials Science and Engineering, vol. 49(1), IOP Publishing, 2013, p. 012057, , https://doi.org/10.1088/1757-899X/ 49/1/012057.

[5] S. Cornelius, M. Vinnichenko, N. Shevchenko, A. Rogozin, A. Kolitsch, W. Möller, Achieving high free electron mobility in $\mathrm{ZnO}$ : Al thin films grown by reactive pulsed magnetron sputtering, Appl. Phys. Lett. 94 (4) (2009) 042103, , https://doi.org/10. $1063 / 1.3074373$.

[6] K. Ellmer, A. Klein, B. Rech, Transparent conductive zinc oxide: basics and applications in thin film solar cells, in: R. Hull, R.M. Osgood, Jr.J. Parisi, H. Warlimont (Eds.), Springer Series in Materials Science, Springer, Berlin, 2008, p. 104.

[7] K. Ellmer, T. Welzel, Reactive magnetron sputtering of transparent conductive oxide thin films: role of energetic particle (ion) bombardment, J. Mater. Res. 27 (5) (2012) 765-779, https://doi.org/10.1557/jmr.2011.428.

[8] T. Minami, H. Nanto, S. Takata, Highly conductive and transparent zinc oxide films prepared by rf magnetron sputtering under an applied external magnetic field, Appl. Phys. Lett. 41 (10) (1982) 958-960, https://doi.org/10.1063/1.93355.

[9] H. Agura, A. Suzuki, T. Matsushita, T. Aoki, M. Okuda, Low resistivity transparent conducting Al-doped $\mathrm{ZnO}$ films prepared by pulsed laser deposition, Thin Solid Films 445 (2) (2003) 263-267, https://doi.org/10.1016/S0040-6090(03)01158-1.

[10] A. Anders, Tutorial: reactive high power impulse magnetron sputtering (R-HiPIMS), J. Appl. Phys. 121 (17) (2017) 171101, , https://doi.org/10.1063/1.4978350.

[11] A. Anders, A structure zone diagram including plasma-based deposition and ion etching, Thin Solid Films 518 (15) (2010) 4087-4090, https://doi.org/10.1016/j. tsf.2009.10.145.

[12] E. Wallin, U. Helmersson, Hysteresis-free reactive high power impulse magnetron sputtering, Thin Solid Films 516 (18) (2008) 6398-6401, https://doi.org/10.1016/ j.tsf.2007.08.123.

[13] M. Audronis, V. Bellido-Gonzalez, Hysteresis behaviour of reactive high power impulse magnetron sputtering, Thin Solid Films 518 (8) (2010) 1962-1965, https:// doi.org/10.1016/j.tsf.2009.12.011.

[14] F. Ruske, A. Pflug, V. Sittinger, W. Werner, B. Szyszka, D.J. Christie, Reactive deposition of aluminium-doped zinc oxide thin films using high power pulsed magnetron sputtering, Thin Solid Films 516 (14) (2008) 4472-4477, https://doi.org/ 10.1016/j.tsf.2007.06.019

[15] M. Mickan, U. Helmersson, H. Rinnert, J. Ghanbaja, D. Muller, D. Horwat, Room temperature deposition of homogeneous, highly transparent and conductive Aldoped $\mathrm{ZnO}$ films by reactive high power impulse magnetron sputtering, Sol. Energy Mater. Sol. Cells 157 (2016) 742-749, https://doi.org/10.1016/j.solmat.2016.07. 020 .

[16] M. Mickan, U. Helmersson, D. Horwat, Effect of substrate temperature on the deposition of Al-doped $\mathrm{ZnO}$ thin films using high power impulse magnetron sputtering, Surf. Coat. Technol. 347 (2018) 245-251, https://doi.org/10.1016/j. surfcoat.2018.04.089.

[17] K. Ellmer, F. Kudella, R. Mientus, R. Schieck, S. Fiechter, Influence of discharge parameters on the layer properties of reactive magnetron sputtered $\mathrm{ZnO}$ : $\mathrm{Al}$ films, Thin Solid Films 247 (1) (1994) 15-23, https://doi.org/10.1016/0040-6090(94) 90470-7.

[18] S. Jäger, B. Szyszka, J. Szczyrbowski, G. Bräuer, Comparison of transparent conductive oxide thin films prepared by ac and dc reactive magnetron sputtering, Surf. Coat. Technol. 98 (1-3) (1998) 1304-1314, https://doi.org/10.1016/S0257 8972(97)00145-X.

[19] F. Moens, S. Konstantinidis, D. Depla, The target material influence on the current pulse during high power pulsed magnetron sputtering, Front. Phys. 5 (2017) 51, https://doi.org/10.3389/fphy.2017.00051.

[20] J.T. Gudmundsson, N. Brenning, D. Lundin, U. Helmersson, High power impulse magnetron sputtering discharge, J. Vac. Sci. Technol. A 30 (3) (2012) 030801, , https://doi.org/10.1116/1.3691832.

[21] S.M. Rossnagel, Gas density reduction effects in magnetrons, J. Vac. Sci. Technol. A 6 (1) (1988) 19-24, https://doi.org/10.1116/1.574988.

[22] D.W. Hoffman, A sputtering wind, J. Vac. Sci. Technol. A 3 (3) (1985) 561-566, https://doi.org/10.1116/1.572994.

[23] B. Liebig, N.S.J. Braithwaite, P.J. Kelly, J.W. Bradley, Spatial and temporal investigation of high power pulsed magnetron discharges by optical 2D-imaging, Thin Solid Films 519 (5) (2010) 1699-1704, https://doi.org/10.1016/j.tsf.2010.06.055.

[24] J. Vlcek, A.D. Pajdarova, P. Belsky, J. Lukas, P. Kudlacek, J. Musil, Characterization of high-power pulsed dc magnetron discharges for ionized high-rate sputtering of copper films, Society of Vacuum Coaters 48 Th Annual Technical Conference Proceedings, 2005, pp. 465-469 https://www.svc.org/DigitalLibrary/document. $\mathrm{cfm} / 1145$ /Characterization-of-High-power-Pulsed-dc-Magnetron-Discharges-forIonized-High-rate-Sputtering-of-Copper-Films.

[25] M. Samuelsson, D. Lundin, J. Jensen, M.A. Raadu, J.T. Gudmundsson, U. Helmersson, On the film density using high power impulse magnetron sputtering, Surf. Coat. Technol. 205 (2) (2010) 591-596, https://doi.org/10.1016/j. surfcoat.2010.07.041.

[26] J.B. Mann, Ionization cross sections of the elements calculated from mean-square radii of atomic orbitals, J. Chem. Phys. 46 (5) (1967) 1646-1651, https://doi.org/ 10.1063/1.1840917.

[27] J.A. Thornton, Magnetron sputtering: basic physics and application to cylindrical magnetrons, J. Vac. Sci. Technol. 15 (2) (1978) 171-177, https://doi.org/10.1116/ 1.569448 .

[28] K. Sarakinos, J. Alami, S. Konstantinidis, High power pulsed magnetron sputtering: a review on scientific and engineering state of the art, Surf. Coat. Technol. 204 (11) (2010) 1661-1684, https://doi.org/10.1016/j.surfcoat.2009.11.013.

[29] Z. Wu, S. Xiao, Z. Ma, S. Cui, S. Ji, X. Tian, R. Fu, P. Chu, F. Pan, Discharge current modes of high power impulse magnetron sputtering, AIP Adv. 5 (9) (2015) 097178, , https://doi.org/10.1063/1.4932135.

[30] A. Anders, J. Andersson, A. Ehiasarian, High power impulse magnetron sputtering: current-voltage-time characteristics indicate the onset of sustained self-sputtering, J. Appl. Phys. 102 (11) (2007) 113303, , https://doi.org/10.1063/1.2817812.

[31] J.T. Gudmundsson, D. Lundin, N. Brenning, M.A. Raadu, C. Huo, T.M. Minea, An ionization region model of the reactive $\mathrm{Ar} / \mathrm{O} 2$ high power impulse magnetron sputtering discharge, Plasma Sources Sci. Technol. 25 (6) (2016) 065004, , https:// doi.org/10.1088/0963-0252/25/6/065004.

[32] N. Brenning, J.T. Gudmundsson, M.A. Raadu, T.J. Petty, T. Minea, D. Lundin, A unified treatment of self-sputtering, process gas recycling, and runaway for high power impulse sputtering magnetrons, Plasma Sources Sci. Technol. 26 (12) (2017) 125003, , https://doi.org/10.1088/1361-6595/aa959b.

[33] A. Anders, J. Čapek, M. Hála, L. Martinu, The 'recycling trap': a generalized explanation of discharge runaway in high-power impulse magnetron sputtering, J. Phys. D. Appl. Phys. 45 (1) (2011) 012003, , https://doi.org/10.1088/0022-3727/ 45/1/012003.

[34] A. Anders, Self-sputtering runaway in high power impulse magnetron sputtering: 
the role of secondary electrons and multiply charged metal ions, Appl. Phys. Lett. 92 (20) (2008) 201501, , https://doi.org/10.1063/1.2936307.

[35] J. Čapek, M. Hála, O. Zabeida, J.E. Klemberg-Sapieha, L. Martinu, Steady state discharge optimization in high-power impulse magnetron sputtering through the control of the magnetic field, J. Appl. Phys. 111 (2) (2012) 023301, , https://doi. org $/ 10.1063 / 1.3673871$.

[36] T. Kubart, J. Andersson, Modelling of target effects in reactive HIPIMS, IOP Conference Series: Materials Science and Engineering, vol. 39(1), IOP Publishing, 2012012008, , , https://doi.org/10.1088/1757-899X/39/1/012008.

[37] D.J. Christie, Target material pathways model for high power pulsed magnetron sputtering, J. Vac. Sci. Technol. A 23 (2) (2005) 330-335, https://doi.org/10.1116/ 1.1865133.

[38] A. Anders, Deposition rates of high power impulse magnetron sputtering: physics and economics, J. Vac. Sci. Technol. A 28 (4) (2010) 783-790, https://doi.org/10. $1116 / 1.3299267$.

[39] Surface Physics Group at TU Wien, A simple sputter yield calculator, http://www. iap.tuwien.ac.at/www/surface/sputteryield, (2009), Accessed date: 13 September 2018.

[40] P. Raman, J. Weberski, M. Cheng, I. Shchelkanov, D.N. Ruzic, A high power impulse magnetron sputtering model to explain high deposition rate magnetic field configurations, J. Appl. Phys. 120 (16) (2016) 163301, , https://doi.org/10.1063/1. 4965875 .
[41] B. Wu, I. Haehnlein, I. Shchelkanov, J. McLain, D. Patel, J. Uhlig, B. Jurczyk, Y. Leng, D.N. Ruzic, Cu films prepared by bipolar pulsed high power impulse magnetron sputtering, Vacuum 150 (2018) 216-221, https://doi.org/10.1016/j. vacuum.2018.01.011.

[42] K. Ellmer, Resistivity of polycrystalline zinc oxide films: current status and physical limit, J. Phys. D. Appl. Phys. 34 (21) (2001) 3097, https://doi.org/10.1088/00223727/34/21/301.

[43] K.E. Knutsen, A. Galeckas, A. Zubiaga, F. Tuomisto, G.C. Farlow, B.G. Svensson, A.Y. Kuznetsov, Zinc vacancy and oxygen interstitial in $\mathrm{ZnO}$ revealed by sequential annealing and electron irradiation, Phys. Rev. B 86 (12) (2012) 121203, , https:// doi.org/10.1103/PhysRevB.86.121203.

[44] K. Ellmer, R. Mientus, Carrier transport in polycrystalline transparent conductive oxides: a comparative study of zinc oxide and indium oxide, Thin Solid Films 516 (14) (2008) 4620-4627, https://doi.org/10.1016/j.tsf.2007.05.084.

[45] J. Tauc, R. Grigorovici, A. Vancu, Optical properties and electronic structure of amorphous germanium, Phys. Status Solidi B 15 (2) (1966) 627-637, https://doi. org/10.1002/pssb.19660150224.

[46] E. Burstein, Anomalous optical absorption limit in InSb, Phys. Rev. 93 (3) (1954) 632, https://doi.org/10.1103/PhysRev.93.632.

[47] G. Haacke, New figure of merit for transparent conductors, J. Appl. Phys. 47 (9) (1976) 4086-4089, https://doi.org/10.1063/1.323240. 